\title{
The Effect of Faster Engine Response on the Lateral Directional Control of a Damaged Aircraft
}

\author{
Ryan D. May
}

ASRC Aerospace Corporation, Cleveland, Ohio

Kimberly A. Lemon, Jeffrey T. Csank, Jonathan S. Litt, and Ten-Huei Guo

Glenn Research Center, Cleveland, Ohio 


\section{NASA STI Program . . . in Profile}

Since its founding, NASA has been dedicated to the advancement of aeronautics and space science. The NASA Scientific and Technical Information (STI) program plays a key part in helping NASA maintain this important role.

The NASA STI Program operates under the auspices of the Agency Chief Information Officer. It collects, organizes, provides for archiving, and disseminates NASA's STI. The NASA STI program provides access to the NASA Aeronautics and Space Database and its public interface, the NASA Technical Reports Server, thus providing one of the largest collections of aeronautical and space science STI in the world. Results are published in both non-NASA channels and by NASA in the NASA STI Report Series, which includes the following report types:

- TECHNICAL PUBLICATION. Reports of completed research or a major significant phase of research that present the results of NASA programs and include extensive data or theoretical analysis. Includes compilations of significant scientific and technical data and information deemed to be of continuing reference value. NASA counterpart of peer-reviewed formal professional papers but has less stringent limitations on manuscript length and extent of graphic presentations.

- TECHNICAL MEMORANDUM. Scientific and technical findings that are preliminary or of specialized interest, e.g., quick release reports, working papers, and bibliographies that contain minimal annotation. Does not contain extensive analysis.

- CONTRACTOR REPORT. Scientific and technical findings by NASA-sponsored contractors and grantees.
- CONFERENCE PUBLICATION. Collected papers from scientific and technical conferences, symposia, seminars, or other meetings sponsored or cosponsored by NASA.

- SPECIAL PUBLICATION. Scientific, technical, or historical information from NASA programs, projects, and missions, often concerned with subjects having substantial public interest.

- TECHNICAL TRANSLATION. Englishlanguage translations of foreign scientific and technical material pertinent to NASA's mission.

Specialized services also include creating custom thesauri, building customized databases, organizing and publishing research results.

For more information about the NASA STI program, see the following:

- Access the NASA STI program home page at http://www.sti.nasa.gov

- E-mail your question via the Internet to help@ sti.nasa.gov

- Fax your question to the NASA STI Help Desk at $443-757-5803$

- Telephone the NASA STI Help Desk at 443-757-5802

- Write to: NASA Center for AeroSpace Information (CASI) 7115 Standard Drive Hanover, MD 21076-1320 
NASA/TM-2012-217216

AIAA-2011-6307

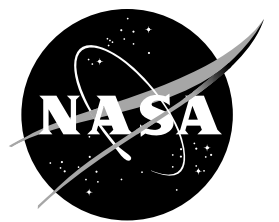

\section{The Effect of Faster Engine Response on the Lateral Directional Control of a Damaged Aircraft}

Ryan D. May

ASRC Aerospace Corporation, Cleveland, Ohio

Kimberly A. Lemon, Jeffrey T. Csank, Jonathan S. Litt, and Ten-Huei Guo

Glenn Research Center, Cleveland, Ohio

Prepared for the

Guidance, Navigation, and Control Conference

sponsored by the American Institute of Aeronautics and Astronautics

Portland, Oregon, August 8-11, 2011

National Aeronautics and

Space Administration

Glenn Research Center

Cleveland, Ohio 44135 


\section{Acknowledgments}

The authors would like to thank Nhan Nguyen of the NASA Ames Research Center for providing us with the Generic Transport Model and insight into the damage models. Additional thanks go to Brian Hinson of Wichita State University for assistance with developing the simulation trim routine. Finally, our thanks to the NASA Aviation Safety Program's Integrated Resilient Aircraft Control project for funding this work $\square$

Level of Review: This material has been technically reviewed by technical management.

Available from

NASA Center for Aerospace Information 7115 Standard Drive

Hanover, MD 21076-1320
National Technical Information Service 5301 Shawnee Road Alexandria, VA 22312

Available electronically at http://www.sti.nasa.gov 


\title{
The Effect of Faster Engine Response on the Lateral Directional Control of a Damaged Aircraft
}

\author{
Ryan D. May \\ ASRC Aerospace Corporation \\ Cleveland, Ohio 44135 \\ Kimberly A. Lemon, Jeffrey T. Csank, Jonathan S. Litt, and Ten-Huei Guo \\ National Aeronautics and Space Administration \\ Glenn Research Center \\ Cleveland, Ohio 44135
}

\begin{abstract}
The integration of flight control and propulsion control has been a much discussed topic, especially for emergencies where the engines may be able to help stabilize and safely land a damaged aircraft. Previous research has shown that for the engines to be effective as flight control actuators, the response time to throttle commands must be improved. Other work has developed control modes that accept a higher risk of engine failure in exchange for improved engine response during an emergency. In this effort, a nonlinear engine model (the Commercial Modular Aero-Propulsion System Simulation 40k) has been integrated with a nonlinear airframe model (the Generic Transport Model) in order to evaluate the use of enhanced-response engines as alternative yaw rate control effectors. Tests of disturbance rejection and command tracking were used to determine the impact of the engines on the aircraft's dynamical behavior. Three engine control enhancements that improve the response time of the engine were implemented and tested in the integrated simulation. The enhancements were shown to increase the engine's effectiveness as a yaw rate control effector when used in an automatic feedback loop. The improvement is highly dependent upon flight condition; the airframe behavior is markedly improved at low altitude, low speed conditions, and relatively unchanged at high altitude, high speed.
\end{abstract}

\section{Nomenclature}

$\begin{array}{ll}\text { C-MAPSS40k } & \text { Commercial Modular Aero-Propulsion System Simulation } 40,000 \mathrm{lb}_{\mathrm{f}} \\ \text { EPR } & \text { Engine Pressure Ratio } \\ \text { Fgross } & \text { Gross engine thrust }\left(\mathrm{lb}_{\mathrm{f}}\right) \\ \text { GTM } & \text { Generic Transport Model } \\ \text { HPC } & \text { High Pressure Compressor } \\ \text { HSI } & \text { High Speed Idle control mode } \\ \text { LPC } & \text { Low Pressure Compressor } \\ p & \text { Roll rate (deg/s) } \\ \text { PLA } & \text { Power Lever Angle } \\ r & \text { Yaw rate (deg/s) } \\ \beta & \text { Side-slip angle (deg) } \\ \Phi & \text { Roll angle (deg) }\end{array}$

\subsection{Introduction}

There is on-going work to develop a means to stabilize a commercial aircraft that has sustained damage, and then enable that aircraft to land safely. One of the proposed means is the use of the propulsion system to supplement or replace the normal flight controls in cases where there is airframe damage or loss of flight control capability (Ref. 1). Specifically of interest is the use of the engines to 
provide differential thrust to stabilize and assist in maneuvering the aircraft on approach in the presence of damage to the vertical stabilizer or rudder. Previous research has found that the turbofan engines on commercial aircraft respond too slowly to pilot input to serve effectively as flight actuators (Ref. 2). To mitigate this problem, techniques are being studied to speed up the response of commercial aircraft engines.

Previously, The Boeing Company has studied the impact of reducing the engine time constant on the dynamic response of a damaged airframe (Ref. 3). In this study, a simplified engine model was integrated into an airframe model and the impact of reducing the engine time constant by 50 percent and by 75 percent was evaluated. They found that decreasing the time constant resulted in better damping of the airframe's dutch roll mode as well as improved yaw damping in cases of rudder failure. The work described in this paper serves to extend Boeing's work by utilizing publicly available airframe and engine simulations and by investigating additional damage cases using a more realistic engine simulation.

Research at the NASA Ames Research Center has also investigated the impact of reducing engine time constant on aircraft behavior (Ref. 4). In this study, a linearized version of a publicly available airframe model, the Generic Transport Model, was used with a simplified, second order engine model with time delay to investigate the potential to stabilize an aircraft with rudder failure and with complete loss of the vertical stabilizer. The results suggest that for the case of rudder failure, differential thrust can be used to stabilize the aircraft. However, in the case of complete vertical stabilizer loss at cruise, the required engine response is very fast and may not be achievable with current hardware. Additionally it was suggested that propulsion control for lateral directional stability would be more effective at low speed and low altitude than high speed and high altitude because engines produce less thrust at cruise due to the significant decrease in air density. Therefore, the work described in the current paper has primarily investigated the effectiveness of using differential thrust for the case of vertical stabilizer failure on approach.

The past research has used linear or simplified engine models and the engine modifications used have been implemented by changing the model's effective time constant. To better assess the potential benefit of enhanced-response engines for controlling the lateral directional behavior of a damaged airframe, a more realistic engine simulation that includes feasible enhanced control modes is needed.

Three enhanced propulsion control modes have been proposed and described in detail in References 5 to 7 . These modes have been found to increase the rate at which an engine responds to pilot throttle commands when implemented in a generic engine simulation. In order to determine the effectiveness of these enhanced engine control modes on improving the lateral directional stability of a damaged aircraft, a combined airframe/engine simulation was developed.

The engine simulation used is the Commercial Modular Aero-Propulsion System Simulation 40k (C-MAPSS40k) (Ref. 8). This software is a publicly available, MATLAB/Simulink (The Mathworks, Inc.) based, generic, high-bypass, twin-spool, commercial turbofan engine simulation that produces 35,000 to 40,000 pounds of thrust - comparable to those found on twin-engine, 200 passenger commercial aircraft. C-MAPSS40k is a physics-based model that exhibits the highly nonlinear behavior found in commercial aircraft engines. Two copies of this engine simulation were integrated into the NASA Generic Transport Model (GTM). The GTM is a dynamic simulation of a twin-engine, generic commercial aircraft, written in MATLAB/Simulink. The dynamic characteristics of the GTM are based on wind-tunnel testing, computational geometric modeling, computational fluid dynamics, and the vortex lattice method (Ref. 9). The GTM includes damage models that allow for the simulation of six levels of vertical stabilizer damage (Ref. 10), thus allowing the study of the ability of the enhanced engine control modes to preserve the controllability of the aircraft with various levels of damage. The failure scenarios investigated involve damage to the vertical stabilizer and rudder, either during approach or at cruise, followed by an effort to stabilize the aircraft and maneuver for safe landing.

This paper describes the testing of the impact of engines with enhanced control modes on the controllability of the GTM airframe simulation in the presence of airframe damage. Section 2.0 briefly describes a nominal engine controller as well as the enhanced control modes and how they are implemented in the propulsion system simulation. An overview of the GTM and modifications necessary 
for this work are described in Section 3.0. The integration of the flight control and propulsion control systems is discussed in Section 4.0. Section 5.0 presents results of various simulated emergency scenarios, leading to some conclusions and a discussion of future work in Section 6.0.

\subsection{Faster Engine Response}

A typical commercial aircraft engine control system is comprised of two main components: power management and protection logic (Ref. 11). The power management controller is designed to regulate engine performance at a specified power level. Ideally, the pilot would be able to command a thrust level. However, thrust is not measurable while in flight and so alternate parameters are used - typically either fan speed or engine pressure ratio (EPR). Each of these signals is directly related to the thrust output and can serve as an indicator of the thrust level. The pilot's throttle position is converted to a fan speed or EPR setpoint and maintained there with a proportional-integral controller. The throttle command used in C-MAPSS40k is referred to as the power lever angle (PLA), which ranges from a flight idle setting of $40^{\circ}$ to maximum power at $80^{\circ}$.

The other component of the engine control system is the protection logic, whose purpose is to ensure the safe operation of the engine. First, the engine needs to be operated in such a way that no component will fail. This means protecting components such as turbine disks, rotor blades, and combustor casing from exceeding their acceptable stress levels. To ensure this, engine pressures and shaft speeds are monitored and prevented from exceeding a maximum limit. The second aspect to "safe operation" is the prevention of compressor surge. Surge occurs when a compressor can no longer maintain the necessary pressure ratio, resulting in a reversal of flow through the engine, a sudden loss of engine thrust, and potentially severe damage to engine components. The High Pressure Compressor (HPC) will generally surge during throttle increases and the Low Pressure Compressor (LPC) will typically surge during a throttle decrease. Unfortunately, there is currently no means to directly measure how close the engine is to surging; however, there are a number of indirect means to prevent compressor surge (Ref. 12). In C-MAPSS40k, HPC surge is prevented by the use of an acceleration limit. This limit prevents the core shaft from accelerating faster than a preset limit based on the current core speed. The faster the core shaft is spinning the more acceleration is allowed. LPC surge on deceleration is prevented by ensuring that the fuel flow rate to the engine does not decrease too quickly. Decelerations are typically quicker than accelerations and thus this work has focused on increasing the rate of engine acceleration. The specific details of the protection logic implemented in the nominal C-MAPSS40k engine controller can be found in Reference 11.

The resulting closed loop propulsion system is highly nonlinear: power transients have very different characteristics at different flight conditions and thrust levels; power increases and decreases have significantly different responses due to each having different constraints; and maximum and minimum engine thrust is limited based on the flight condition. All of these nonlinearities will have a large impact on the use of the propulsion system as a flight control effector. However, for the purposes of this paper they will not be explicitly addressed even though they will manifest themselves in the simulations; study of the impact of engine nonlinearities and compensation techniques will be left to future work.

To enable the engine to respond faster than nominal, the C-MAPSS40k control system has been modified to include enhanced control modes (Ref. 6). The remainder of this section briefly describes the three enhanced control modes that have been implemented to improve the response of the engine to pilot commands: (1) increase in the power management controller's bandwidth, (2) relaxation of the protection logic's acceleration limiter, and (3) addition of High Speed Idle mode. For the full details of each enhanced control mode see References 5 to 7 . Each of these control modes serves a different purpose and the intention is that the combination of all of them will produce the engine response desired. Further, it should be noted that each of these enhancements carries a non-negligible risk to the engine. This increase in engine risk may be acceptable if it improves the survivability of the aircraft (Ref. 13).

Increasing the bandwidth of the power management controller is a straightforward change that results in faster response at the risk of overshooting of the thrust target (Ref. 5). The modification results in 
approximately a 25 percent decrease in the rise time and settling time of a small 4,000 $\mathrm{lb}_{\mathrm{f}}$ transient during approach flight conditions. This modification can be achieved by increasing the proportional gain or integral gain of the power management controller. There is limited impact on the response to large throttle changes as transient performance is primarily governed by the protection logic.

To improve the response to large throttle increases, the acceleration limit is relaxed. This will clearly result in improved performance, however it is critical that the HPC not surge even with this modified limit. The risk of surge is highly dependent on flight condition, engine age, and even minor differences between engines. A conservative increase was implemented for this study as an engine surge during an emergency situation would likely prove disastrous. Based on data in Reference 5, this conservative modification results in a 20 percent average decrease in thrust delay time and a 15 percent decrease in settling time for a throttle increase from idle to full power.

The final modification is the implementation of a control mode called High Speed Idle (HSI) (Refs. 5 and 7). During approach and landing, the engine thrust is required to be low to maintain an appropriate landing speed. In situations where the engine's power level has to be increased significantly, there is a large delay between the throttle input and engine thrust response due to the need to prevent HPC surge. To mitigate this, the HSI control mode increases the engine idle limit, resulting in faster core shaft speed. The additional thrust produced is then nearly eliminated by shunting air away from the engine core through various bleed systems. Because of the increase in core speed, there is less risk of HPC surge, thus HSI can be augmented with an increased acceleration limit. This change results in an approximate 30 percent reduction in delay time and 17 percent reduction in settling time for flight idle to full power transients during approach.

The engine responses to a full throttle range step input are shown in Figure 1. Each plot compares the nominal engine response (blue line) to that of an engine with all of the above enhanced control modes (red line). Plot "a" is taken at approach while plot " $b$ " is executed at cruise. It is clear from the plots alone that the enhanced engines respond faster than the nominal engines in both cases. However, the improvement is much more striking at approach due to the fact that the engine produces a much larger thrust range and thus spends most of the transient at the acceleration limit. That the High Speed Idle enhancement is active on approach can be seen in the fact that the enhanced engine is producing slightly more thrust than the nominal engine prior to the transient.
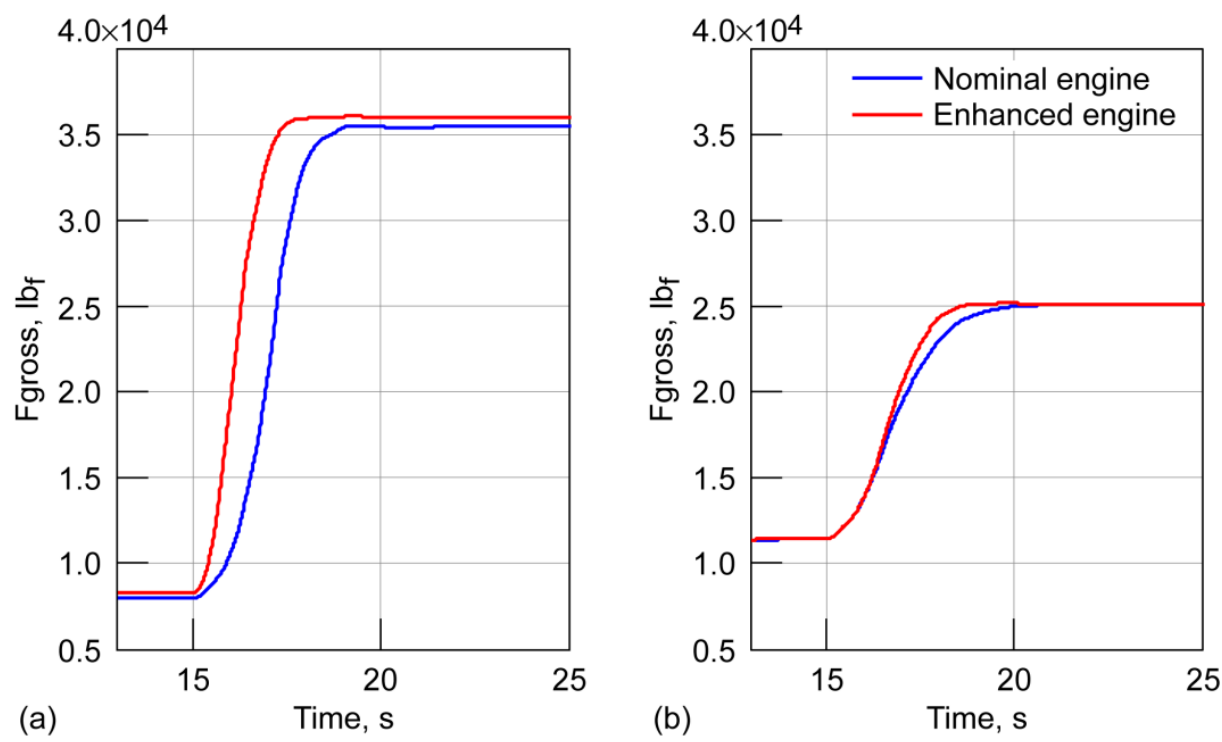

Figure 1.-Comparison of response of a nominal engine (blue) and enhanced engine (red) to a full throttle range step input at $15 \mathrm{~s}$. Plot (a) is taken at approach (1,000 ft, Mach 0.221) and plot (b) is at cruise (30,000 ft, Mach 0.8). 
All of the enhanced control modes are enabled during the emergency scenario tests. Their usage and effect will be highly dependent on the age of the engine and the size of the throttle movements commanded. All tests will require that the engines perform safely, specifically that they do not surge. For brevity, engines that have been modified to include all of the above enhanced control modes will be referred to as enhanced engines. Engines without the modifications will be referred to as nominal engines.

\subsection{Airframe Model}

The NASA developed full-scale Generic Transport Model (GTM) is used as the aircraft simulation in this research effort. This representation of a typical twin engine transport aircraft was developed through extensive modeling work involving scaled model testing and computational techniques (Ref. 9). The GTM is a MATLAB/Simulink based simulation, which allows for easy integration with the C-MAPSS40k engine simulation. The aircraft dynamics are modeled following the six degrees of freedom body fixed equations of motion (Ref. 14). The stability and control derivatives are determined based on look-up tables according to angle of attack, sideslip angle, Mach number, and damage case. The GTM is capable of modeling a variety of failure types, however for this research we will only focus on the spanwise failures to the vertical tail. Each failure case causes a shift in aircraft center of gravity and change in aircraft mass. Additionally, each vertical stabilizer failure case results in a complete loss of rudder control effectiveness.

A simplified flight control architecture is supplied with the GTM to maintain aircraft stability and follow pitch rate, roll rate, and yaw rate commands. These commands are input into a reference model that generates the expected pitch, roll, and yaw rates. The actual rates are then driven to the expected values by a Proportional-Integral (PI) control law that commands the aileron, elevator, and rudder positions. The flight control surface actuator dynamics are modeled and they have a limited range of travel to capture saturation effects. The controller is straightforward; it consists of constant PI gains and an airframe reference model that is a simple first order system. There is logic to coordinate turns, but in general the yaw rate, roll rate, and pitch rate are controlled independently.

\subsection{Integrated Flight/Propulsion Control}

Since this simulation is not piloted, it is necessary to have the flight control system capable of actuating the engines differentially to stabilize and maneuver the aircraft. For this initial evaluation, we follow the lead of References 3 and 4 by constructing a feedback loop from aircraft body axis yaw rate to a differential throttle command using a proportional controller as shown in Figure 2. It is important to note that the airframe reference yaw rate (r_reference) is the target yaw rate from the flight control reference model. In cases of rudder damage, the rudder command influences the reference yaw rate even though the actuator is disabled. This allows the engines to assist or stand in for the rudder when responding to rudder pedal commands in addition to external disturbances. Additionally, since the automatic control loop only modifies differential throttle, the nominal throttle can be changed at will.

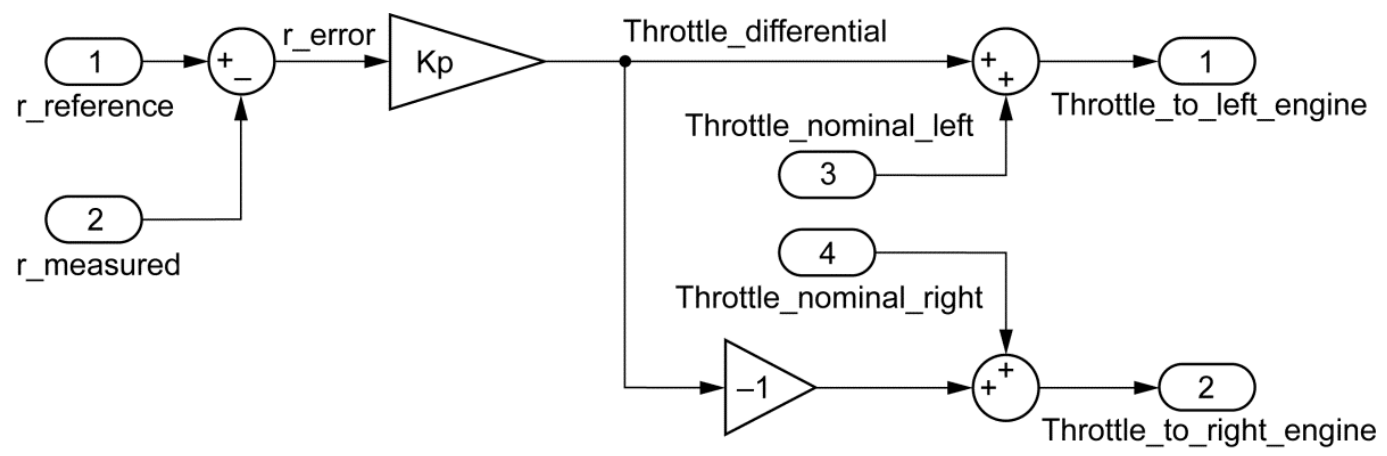

Figure 2.-Feedback from yaw rate to differential throttle commands. 
It is worth restating the earlier point that the gas turbine engine is highly nonlinear, especially when coupled with the necessary control and protection logic. While the effects of thrust saturation and throttle increase/decrease differences will not be addressed here, the proportional gain $(K p)$ is tuned independently for each flight condition and for nominal and enhanced engine operation mode with the objective of minimizing settling time. It should be possible to create a full envelope control law based on gain scheduling at various breakpoints, however this is beyond the scope of this investigation.

\subsection{Simulation Results}

In order to produce results comparable to those in Reference 4, two flight cases were selected for testing. The first, approach at an altitude of $1,000 \mathrm{ft}$ at Mach 0.221 , was chosen based on the conclusion that engines can be more effective actuators at low altitude and low speed. The second, cruise, is the same as in Reference 4 with an altitude of 30,000 ft and a speed of Mach 0.8. Additionally, the vertical stabilizer damage model utilized in all damage scenarios, a spanwise structural break of the vertical stabilizer at 50 percent of total span, is referred to as damage model C2 (Ref. 4). This damage case was chosen to balance loss of stability due to the damage with the yaw resistance of the remaining section. When the vertical stabilizer is completely removed, the engines require less differential thrust to effect a yaw rate change than when the vertical stabilizer is intact. However, the greater the damage, the greater the reduction in directional stability; thus, if the engines can stabilize the airframe, they will allow greater maneuvering capability as vertical stabilizer damage increases.

For the situation in which an aircraft is damaged there are three main objectives: (1) stabilize the aircraft, (2) maneuver the plane to enable a safe landing, and (3) land the aircraft. The GTM is not designed to simulate landings and thus we have focused on the first two objectives.

\section{$5.1 \quad$ Test 1: Stabilization}

The primary objective of stabilization is to drive the angular rates to zero as quickly as possible in the face of a disturbance to the airframe. While this will leave the actual aircraft angular positions at new values, the pilot (or flight control system) can return to a nominal attitude using the maneuvering capability shown in the next section. For our case of vertical stabilizer damage and resulting loss of rudder control, we are primarily concerned with using the engines to attenuate the yaw rate disturbance, leaving the other degrees of freedom to the flight control surfaces. In this example, the damaged aircraft with nominal engines is compared to one with faster-responding engines, both with yaw rate feedback. All of the stabilization tests discussed here are initialized at stable, undamaged flight. At $20 \mathrm{~s}$, damage to the vertical stabilizer occurs simultaneously with a one-second long positive disturbance to yaw rate and a negative disturbance to roll rate. The magnitudes of the disturbances were arbitrarily chosen to allow for visual examination of the impact of the engines on the airframe's stability. The case of damage stabilization during approach is shown in Figure 3 for a $7.2 \mathrm{deg} / \mathrm{s}$ disturbance to yaw rate and a $-0.72 \mathrm{deg} / \mathrm{s}$ disturbance to roll rate. It is immediately noticeable that the airframe roll angle and side-slip angle are smoother when the enhanced engines are used than when the nominal engines are used. Examining the yaw rate, the airframe with enhanced engines stabilizes approximately $5 \mathrm{~s}$ faster than that with nominal engines ( 24.06 vs. 29.28 s). Further, the total control effort with enhanced engines is markedly less than the nominal engines. 

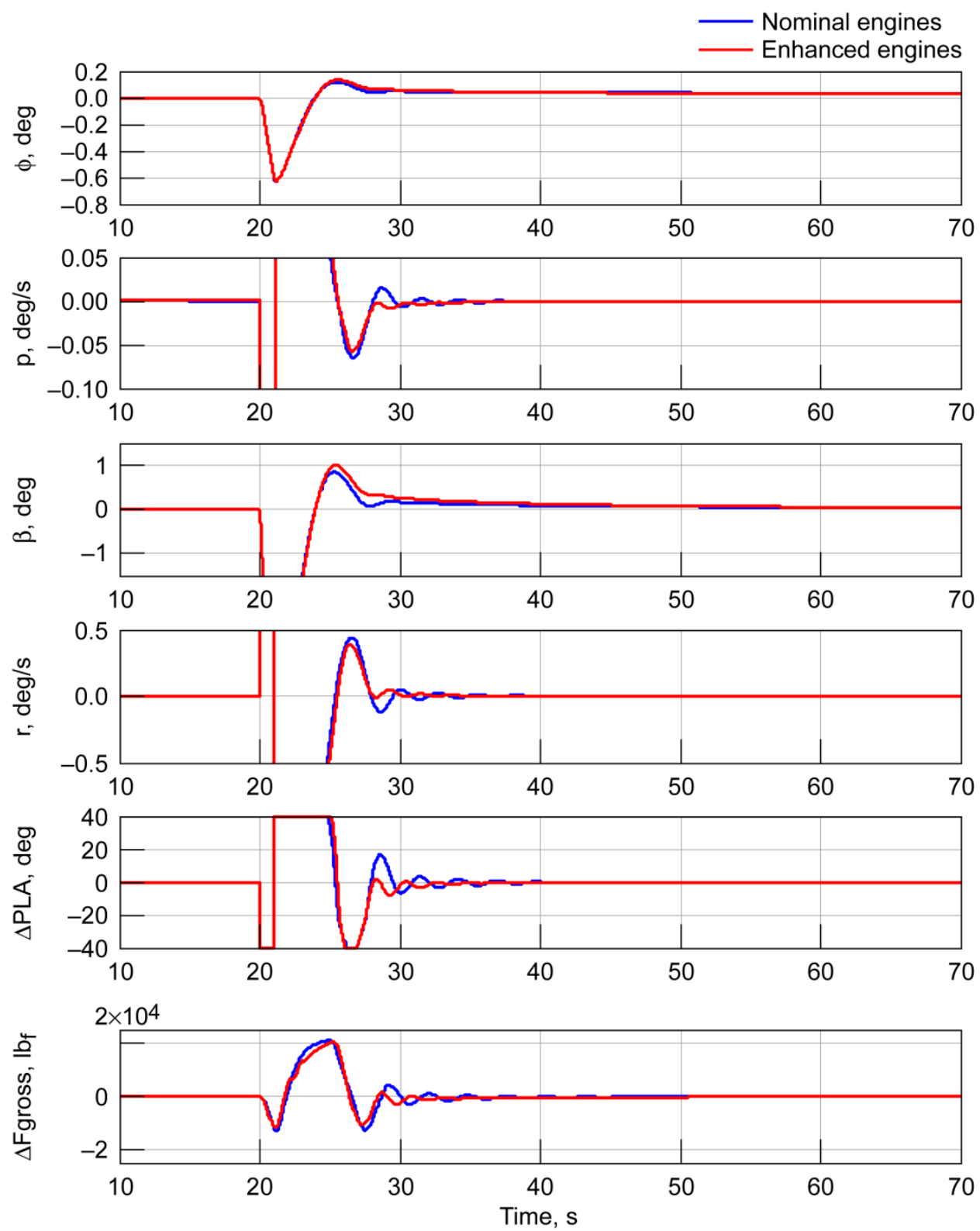

Figure 3.-Airframe stabilization at approach (1,000 ft, Mach 0.221, gear deployed, full flaps) with vertical stabilizer damage (C2) with nominal engines (blue) and enhanced engines (red) under a $1 \mathrm{~s}$ disturbance of $7.2 \mathrm{deg} / \mathrm{s}$ to yaw rate and $-0.72 \mathrm{deg} / \mathrm{s}$ to roll rate injected at $20 \mathrm{~s}$. The $\triangle P L A$ and $\Delta$ Fgross plots are the differential throttle command and differential gross engine thrust, respectively. Note: Some data is truncated to show the dynamics of the response.

If we examine the case of stabilization with vertical stabilizer damage at cruise (shown in Fig. 4) we find that the airframe behaves essentially identically for both nominal and enhanced engines. There is a slight decrease in the total required control effort (the integral of the magnitude of $\Delta$ Fgross) of the system with enhanced engines, but the impact is negligible. The yaw rate is not stabilized for nearly $40 \mathrm{~s}$ - nearly twice as long as the aircraft at approach with enhanced engines. It is also interesting to note that the relatively low frequency oscillation in yaw rate in this example results in throttle commands to the engines that are much slower here than in the approach case shown in Figure 3. It appears that the 

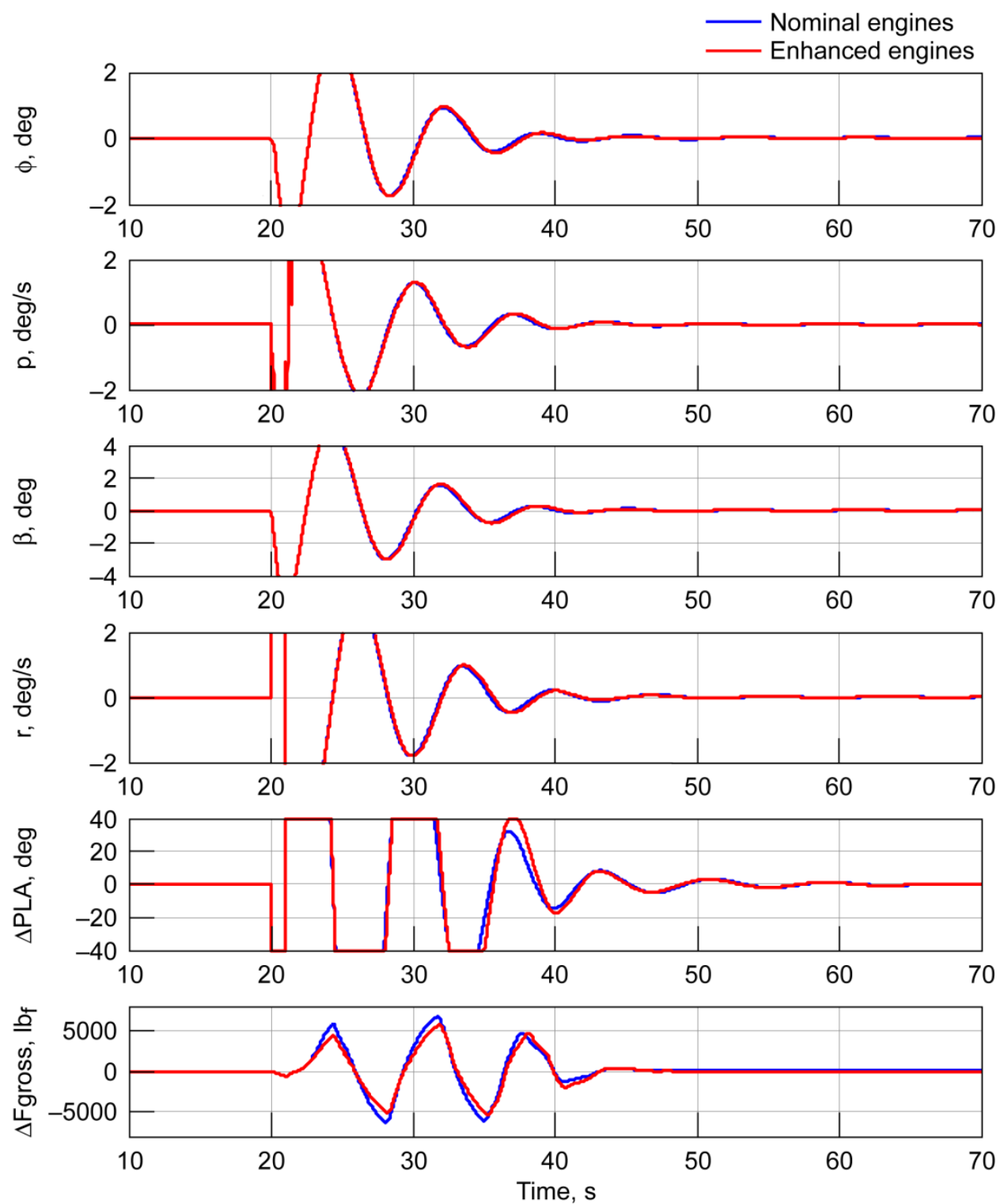

Figure 4.-Airframe stabilization at cruise $(30,000 \mathrm{ft}$, Mach 0.8$)$ with vertical stabilizer damage (C2) with nominal engines (blue) and enhanced engines (red) under a $1 \mathrm{~s}$ disturbance of $8.6 \mathrm{deg} / \mathrm{s}$ in yaw rate and $-2.9 \mathrm{deg} / \mathrm{s}$ in roll rate injected at $20 \mathrm{~s}$. Note: Some data is truncated to show the dynamics of the response.

airframe oscillatory mode excited by the damage and disturbance is at a much lower frequency at cruise than when at approach. Most likely, the fact that the throttle commands are slow is responsible for the nominal engine being as effective as the enhanced engine; both are fast enough to keep up with the throttle commands, whereas in the approach case the enhanced engine is better able to meet the faster commands. It should be noted that the frequency response difference may be attributed to the choice of yaw rate to differential throttle gain; however, this gain was chosen to be nearly as large as possible without destabilizing the system. 
The sign of the disturbance components in these examples were chosen because there is a very interesting effect due to the coupling of roll and yaw when using the engines differentially as shown in Figure 5. When the left engine produces more thrust than the right, a positive yaw moment is generated in conjunction with a positive roll moment due to the engines' location below the airframe center of gravity. Therefore, the chosen disturbance results in the engines driving the roll mode out of phase, exacerbating the rolling motion and effectively fighting the ailerons (blue). When the disturbance has the same sign in both yaw and roll (red), the engines assist the ailerons and the aircraft roll rate stabilizes with lower amplitude oscillations and less aileron effort. Note that both disturbances have nearly identical yaw response, thus the throttle position for each case is the same. This highlights the need to more closely integrate the propulsion system with the flight controller for emergency recovery situations.
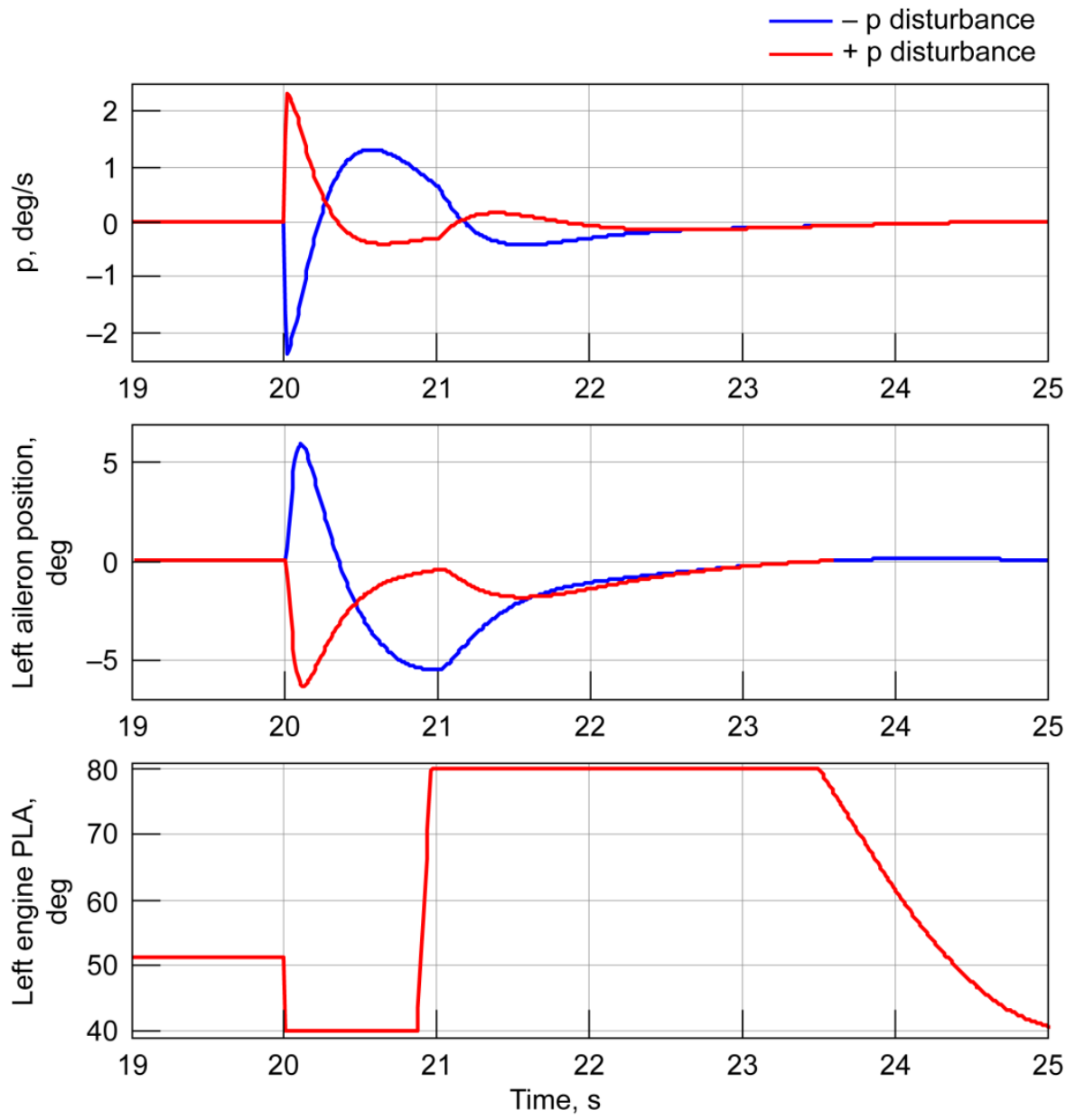

Figure 5.-Airframe stabilization at approach (1,000 ft, Mach 0.221, gear deployed, full flaps) with vertical stabilizer damage (C2) and nominal engines under a $0.1 \mathrm{~s}$ disturbance of $+7.2 \mathrm{deg} / \mathrm{s}$ to yaw rate and both $-0.72 \mathrm{deg} / \mathrm{s}$ to roll rate (blue) and $0.72 \mathrm{deg} / \mathrm{s}$ to roll rate (red) injected at $20 \mathrm{~s}$. 


\subsection{Test 2: Maneuverability}

Once the aircraft has been stabilized, it is critical that the pilot be able to maneuver the plane to safely descend from cruise, get to an airport, and line up with the runway. In this example, a maneuver is executed by issuing a step turn command at $20 \mathrm{~s}$ into the simulation. During approach, this type of maneuver might be used by the pilot or flight control system to line up with a runway.

The response of the GTM with vertical stabilizer damage $\mathrm{C} 2$ with both nominal and enhanced engines is shown in Figure 6. The improvement in airframe response with enhanced engines is dramatic. By examining the raw data we find: the 98 percent sideslip angle settling time is reduced from 23.73 to $5.32 \mathrm{~s}$; the enhanced engines use 61.2 percent less total control effort; and in both cases neither surge margin, as reported by C-MAPSS40k, is close to zero.
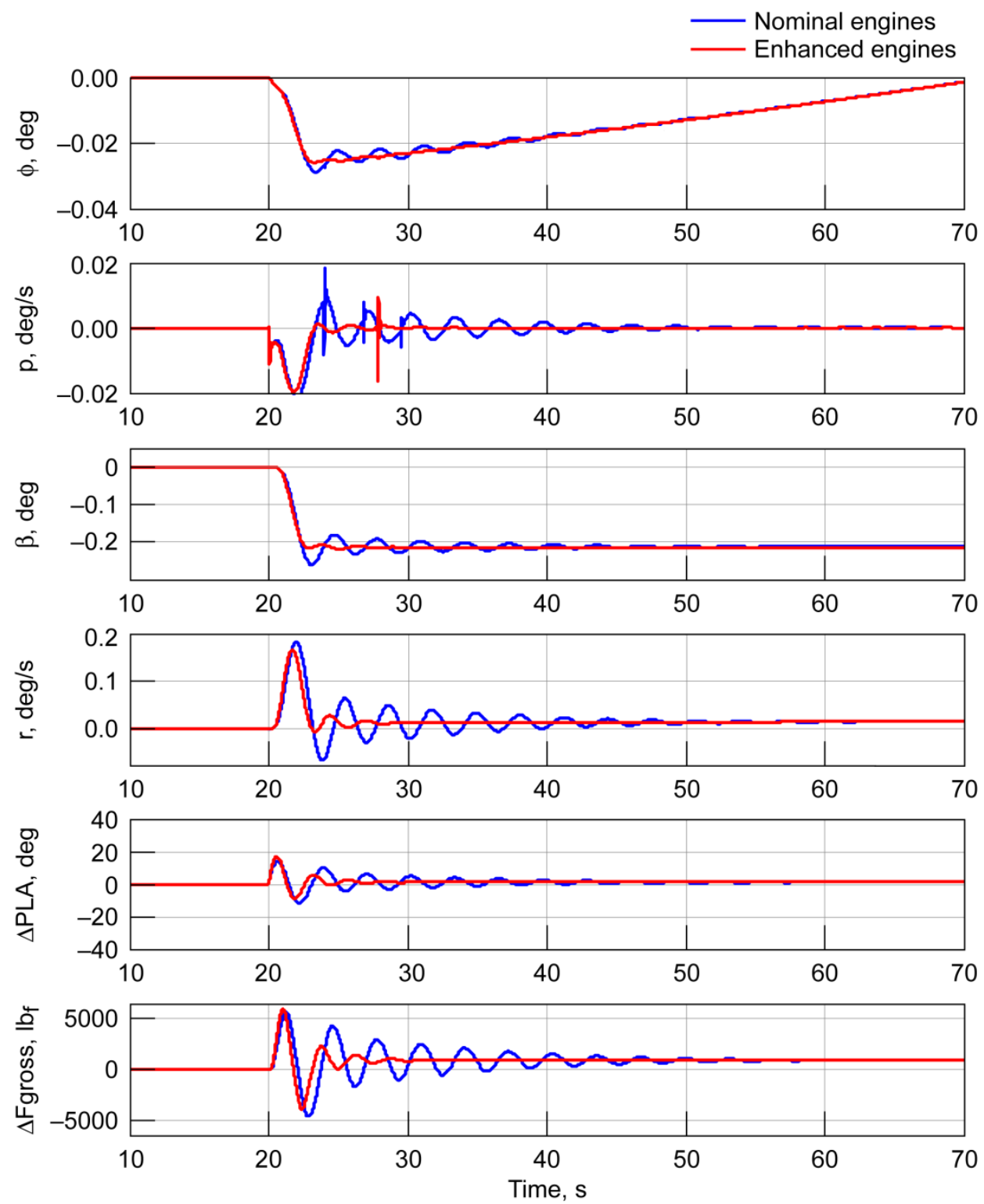

Figure 6.-Airframe response to a turn command at $20 \mathrm{~s}$ during approach $(1,000 \mathrm{ft}$, Mach 0.221 , gear deployed, full flaps) with vertical stabilizer damage (C2) with nominal engines (blue) and enhanced engines (red). There is a numerical instability in the airframe simulation visible in the roll rate plot. 
To get a better understanding of how the airframe utilizing enhanced engines for flight control compares to an aircraft with a functioning rudder, a simulation with no vertical stabilizer damage is conducted. In the cases with nominal and enhanced engines, the rudder is disabled (stuck at the zero position) and the yaw rate is fed back to the differential throttles. For the rudder only case, the rudder is enabled and the yaw rate feedback is disabled. The results of the same turn command are shown in Figure 7. As expected, the case with rudder only control is faster than both engine only cases. However, by examining the plots and raw data, the enhanced engines allow the airframe to perform in a manner quite similar to that of the rudder only: there is more ringing in yaw rate; the initial response is slightly delayed $(0.51 \mathrm{~s})$; and while there is a steady state difference, the settling times are similar (5.44 $\mathrm{s}$ for
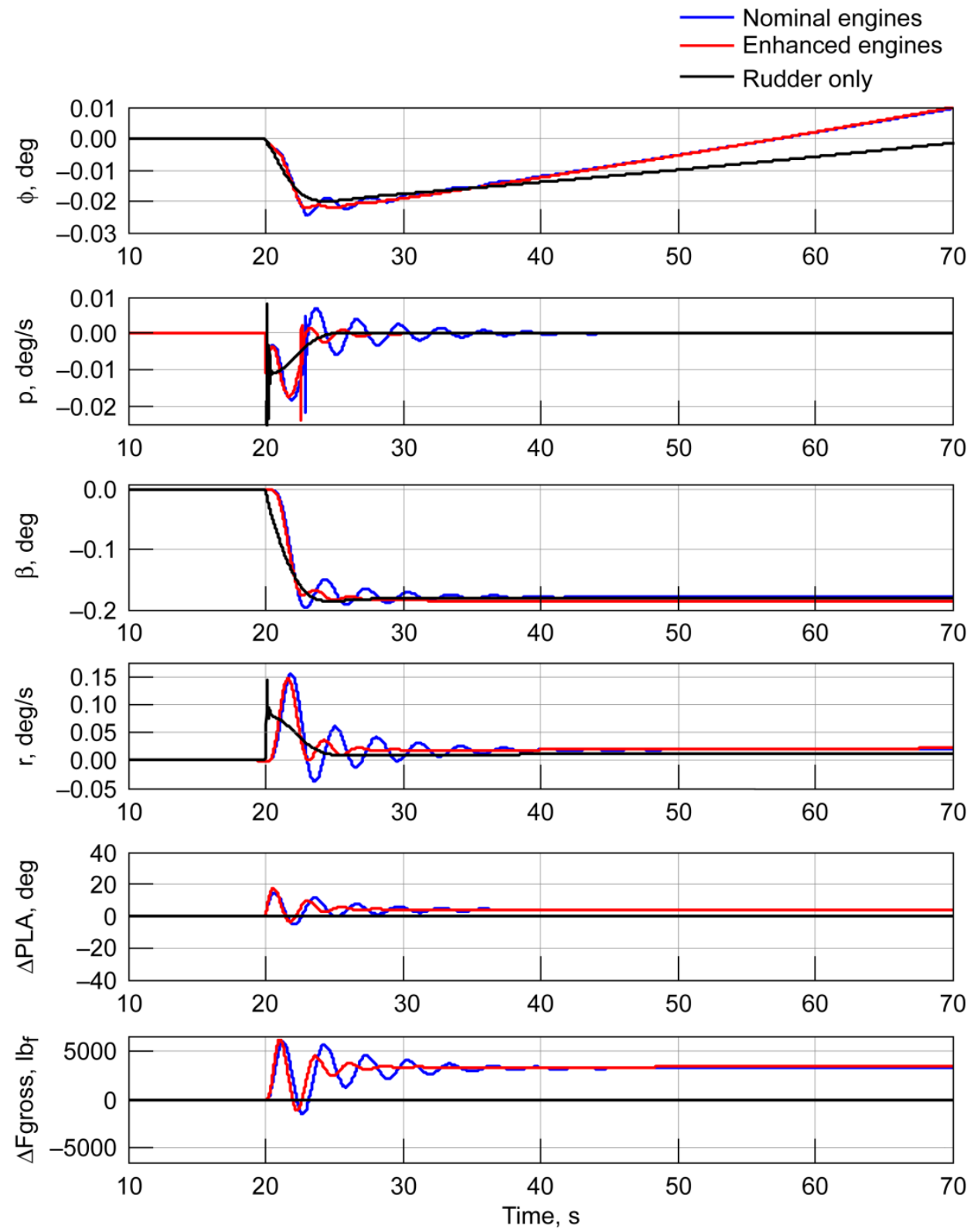

Figure 7.-Airframe response to a turn command during approach (1,000 ft, Mach 0.221 , gear deployed, full flaps) with an undamaged airframe with nominal engines and stuck rudder (blue), enhanced engines and stuck rudder (red), and rudder only control (black). 
rudder only compared to $6.91 \mathrm{~s}$ for enhanced engines). Additionally, comparing the undamaged case (Fig. 7) and the 50 percent vertical stabilizer break case (Fig. 6) it is notable that the steady state differential thrust required is approximately $3,250 \mathrm{lb}_{\mathrm{f}}$ for the undamaged case and $900 \mathrm{lb}_{\mathrm{f}}$ for the $\mathrm{C} 2$ damage case. This highlights the fact that greater engine thrust is required to maneuver in cases with less vertical stabilizer damage.

\subsection{Conclusions and Future Work}

Previous work has shown that a damaged aircraft can be maneuvered by using the engines differentially; however for this to be practically useful in an emergency, the response time of the engines must be improved. Recent studies by NASA and The Boeing Company have shown that the use of a simplified engine model with faster response can improve the damping of the dutch roll mode and yaw damping of a simulated damaged aircraft. The work presented in this paper set out to determine the realistic impact of three enhanced engine control modes that are designed to fit into the current engine control architecture and use only existing actuation and sensors. To achieve this, a realistic, non-linear engine simulation, the Commercial Modular Aero-Propulsion System Simulation 40k (C-MAPSS40k), was integrated into a realistic, non-linear airframe simulation, the NASA Generic Transport Model (GTM), which is capable of simulating realistic airframe damage. An automatic yaw-rate to differential throttle feedback loop was added to integrate the airframe to the engines in order to produce repeatable results. Simulations were conducted on an airframe model with vertical stabilizer damage at cruise and approach flight conditions. The tests consisted of two components: stabilization after the damage and a disturbance; and maneuvering with the damage present. Tests showed that faster engines are more effective at both stabilization and maneuvering than nominal engines; however, the enhancements are more beneficial at approach than at cruise. This is likely due to a number of causes: the fact that gas turbine engines have a much larger thrust range at approach than at cruise, the fact that the High Speed Idle enhanced control mode only operates at approach conditions, and the slower response of the airframe's yaw rate to the differential thrust while at cruise.

All the simulations to this point have been conducted with an automatic feedback loop controlling the throttles differentially. It is important to determine how the results would change if a pilot was using the throttles differentially as well as if a pilot was in the loop with the automatic control. To this end, there is ongoing work at the NASA Glenn Research Center and Boeing to investigate this aspect of the situation in piloted flight simulators. Another piece of significant future work is the closer integration of the propulsion system into the flight control system. Simulations conducted during the current effort have shown that in the presence of some disturbances, the engines and flight control surfaces (specifically the ailerons) can work against each other when the engines are only used to track yaw rate. Additionally, closer integration would allow the engines to augment the flight control surfaces in a much larger range of situations as the engines can be used to change the aircraft's pitch, roll, and yaw depending on airframe configuration.

\section{References}

1. Litt, J.S., Frederick, D.K., and Guo, T.-H., "The Case for Intelligent Propulsion Control for Fast Engine Response,” AIAA 2009-1876, AIAA Infotech@Aerospace Conference, Seattle, WA, June 6-9, 2009.

2. Burcham, F.W., Jr., Fullerton, C.G., and Maine, T.A., "Manual Manipulation of Engine Throttles for Emergency Flight Control," NASA/TM-2004-212045, January 2004.

3. Urnes, J.M. Sr., and Nielsen, Z.A., "Use of Propulsion Commands to Control Directional Stability of a Damaged Transport Aircraft," AIAA 2010-3470, AIAA Infotech@Aerospace Conference, Atlanta, GA, April 20-22, 2010. 
4. Nguyen, N. and Stepanyan, V., "Flight-Propulsion Response Requirements for Directional Stability and Control," AIAA 2010-3471, AIAA Infotech@Aerospace Conference, Atlanta, GA, April 20-22, 2010.

5. Csank, J.T., May, R.D., Litt, J.S., and Guo, T.-H., "A Sensitivity Study of Commercial Aircraft Engine Response for Emergency Situations," NASA/TM-2011-217004.

6. Csank, J.T., Chin, J.C., May, R.D., Litt, J.S., and Guo, T.-H., "Implementation of Enhanced Propulsion Control Modes for Emergency Flight Operation," AIAA-2011-1590, AIAA Infotech@Aerospace Conference, St. Louis, MO, Mar 29-31, 2011.

7. May, R.D., Csank, J.T., Guo, T.-H., and Litt, J.S., "Improving Engine Responsiveness during Approach through High Speed Idle Control," To be published at the 47th AIAA Joint Propulsion Conference \& Exhibit, San Diego, CA, July 31-Aug 3, 2011.

8. May, R.D., Csank, J., Lavelle, T.M., Litt, J.S., and Guo, T.-H., "A High-Fidelity Simulation of a Generic Commercial Aircraft Engine and Controller," AIAA-2010-6630, 46th AIAA Joint Propulsion Conference \& Exhibit, Nashville, TN, July 25-28, 2010.

9. Jordan, T.L., Langford, W.M., et al., "Development of a Dynamically Scaled Generic Transport Model Testbed for Flight Research Experiments," AUVSI Unmanned Systems North America 2004, Arlington, VA, 2004.

10. Shah, G., "Aerodynamic Effects and Modeling of Damage to Transport Aircraft," AIAA Atmospheric Flight Mechanics Conference, AIAA-2008-6203, August 2008.

11. Csank, J., May, R.D., Litt, J.S., and Guo, T.-H., "Control Design for a Generic Commercial Aircraft Engine," AIAA-2010-6629, 46th AIAA Joint Propulsion Conference \& Exhibit, Nashville, TN, July 25-28, 2010.

12. Spang III, A.H., and Brown, H., "Control of Jet Engines," Control Engineering Practice, 8 March 1999, pp. 1043-1059.

13. McGlynn, G.E., Litt, J.S., Lemon, K.A., and Csank, J.T., "A Risk Management Architecture for Emergency Integrated Aircraft Control,” AIAA-2011-1568, Infotech@Aerospace 2011, St. Louis, Missouri, Mar. 29-31, 2011.

14. Roskam, J., “Airplane Flight Dynamics and Automatic Flight Controls Part I,” DAR Corporation, Lawrence, Kansas. 


\begin{tabular}{|c|c|c|}
\hline \multicolumn{2}{|c|}{ REPORT DOCUMENTATION PAGE } & $\begin{array}{l}\text { Form Approved } \\
\text { OMB No. 0704-0188 }\end{array}$ \\
\hline \multicolumn{3}{|c|}{$\begin{array}{l}\text { The public reporting burden for this collection of information is estimated to average } 1 \text { hour per response, including the time for reviewing instructions, searching existing data sources, gathering and maintaining the } \\
\text { data needed, and completing and reviewing the collection of information. Send comments regarding this burden estimate or any other aspect of this collection of information, including suggestions for reducing this } \\
\text { burden, to Department of Defense, Washington Headquarters Services, Directorate for Information Operations and Reports (070404-0188), , } 215 \text { Jefferson Davis Highway, Suite } 1204 \text {, Arlington, VA } 22202-4302 \text {. } \\
\text { Respondents should be aware that notwithstanding any other provision of law, no person shall be subject to any penalty for failing to comply with a collection of information if it does not display a currently valid OMB } \\
\text { control number. } \\
\text { PLEASE DO NOT RETURN YOUR FORM TO THE ABOVE ADDRESS. }\end{array}$} \\
\hline $\begin{array}{l}\text { 1. REPORT DATE (DD-MM-YYYY) } \\
01-03-2012\end{array}$ & $\begin{array}{l}\text { 2. REPORT TYPE } \\
\text { Technical Memorandum }\end{array}$ & 3. DATES COVERED (From - To) \\
\hline \multirow{3}{*}{\multicolumn{2}{|c|}{$\begin{array}{l}\text { 4. TITLE AND SUBTITLE } \\
\text { The Effect of Faster Engine Response on the Lateral Directional Control of a Damaged } \\
\text { Aircraft }\end{array}$}} & 5a. CONTRACT NUMBER \\
\hline & & 5b. GRANT NUMBER \\
\hline & & 5c. PROGRAM ELEMENT NUMBER \\
\hline \multirow{3}{*}{\multicolumn{2}{|c|}{$\begin{array}{l}\text { 6. AUTHOR(S) } \\
\text { May, Ryan, D.; Lemon, Kimberly, A.; Csank, Jeffrey, T.; Litt, Jonathan, S.; Guo, Ten-Huei }\end{array}$}} & 5d. PROJECT NUMBER \\
\hline & & 5e. TASK NUMBER \\
\hline & & $\begin{array}{l}\text { 5f. WORK UNIT NUMBER } \\
\text { WBS 284848.02.06.03.02 }\end{array}$ \\
\hline \multicolumn{2}{|c|}{$\begin{array}{l}\text { 7. PERFORMING ORGANIZATION NAME(S) AND ADDRESS(ES) } \\
\text { National Aeronautics and Space Administration } \\
\text { John H. Glenn Research Center at Lewis Field } \\
\text { Cleveland, Ohio 44135-3191 }\end{array}$} & $\begin{array}{l}\text { 8. PERFORMING ORGANIZATION } \\
\text { REPORT NUMBER } \\
\text { E-17897 }\end{array}$ \\
\hline \multirow{2}{*}{\multicolumn{2}{|c|}{$\begin{array}{l}\text { 9. SPONSORING/MONITORING AGENCY NAME(S) AND ADDRESS(ES) } \\
\text { National Aeronautics and Space Administration } \\
\text { Washington, DC 20546-0001 }\end{array}$}} & $\begin{array}{l}\text { 10. SPONSORING/MONITOR'S } \\
\text { ACRONYM(S) } \\
\text { NASA }\end{array}$ \\
\hline & & $\begin{array}{l}\text { 11. SPONSORING/MONITORING } \\
\text { REPORT NUMBER } \\
\text { NASA/TM-2012-217216 }\end{array}$ \\
\hline \multicolumn{3}{|c|}{$\begin{array}{l}\text { 12. DISTRIBUTION/AVAILABILITY STATEMENT } \\
\text { Unclassified-Unlimited } \\
\text { Subject Category: } 07 \\
\text { Available electronically at http://www.sti.nasa.gov } \\
\text { This publication is available from the NASA Center for AeroSpace Information, 443-757-5802 }\end{array}$} \\
\hline
\end{tabular}

\section{SUPPLEMENTARY NOTES}

\section{ABSTRACT}

The integration of flight control and propulsion control has been a much discussed topic, especially for emergencies where the engines may be able to help stabilize and safely land a damaged aircraft. Previous research has shown that for the engines to be effective as flight control actuators, the response time to throttle commands must be improved. Other work has developed control modes that accept a higher risk of engine failure in exchange for improved engine response during an emergency. In this effort, a nonlinear engine model (the Commercial Modular Aero-Propulsion System Simulation 40k) has been integrated with a nonlinear airframe model (the Generic Transport Model) in order to evaluate the use of enhanced-response engines as alternative yaw rate control effectors. Tests of disturbance rejection and command tracking were used to determine the impact of the engines on the aircraft's dynamical behavior. Three engine control enhancements that improve the response time of the engine were implemented and tested in the integrated simulation. The enhancements were shown to increase the engine's effectiveness as a yaw rate control effector when used in an automatic feedback loop. The improvement is highly dependent upon flight condition; the airframe behavior is markedly improved at low altitude, low speed conditions, and relatively unchanged at high altitude, high speed.

\section{SUBJECT TERMS}

Commercial aircraft; Propulsion system; Engine control

\begin{tabular}{|c|c|c|c|c|c|}
\hline \multicolumn{3}{|c|}{ 16. SECURITY CLASSIFICATION OF: } & \multirow{2}{*}{$\begin{array}{l}\text { 17. LIMITATION OF } \\
\text { ABSTRACT } \\
\text { UU }\end{array}$} & \multirow{2}{*}{$\begin{array}{l}\text { 18. NUMBER } \\
\text { OF } \\
\text { PAGES } \\
19\end{array}$} & \multirow{2}{*}{$\begin{array}{l}\text { 19a. NAME OF RESPONSIBLE PERSON } \\
\text { STI Help Desk (email:help@sti.nasa.gov) } \\
\text { 19b. TELEPHONE NUMBER (include area code) } \\
\text { 443-757-5802 }\end{array}$} \\
\hline $\begin{array}{l}\text { a. REPORT } \\
U\end{array}$ & $\begin{array}{l}\text { b. ABSTRACT } \\
\mathrm{U}\end{array}$ & $\begin{array}{l}\text { c. THIS } \\
\text { PAGE } \\
\text { U }\end{array}$ & & & \\
\hline
\end{tabular}


